ISSN: 0212-5374

DOI: http://dx.doi.org/10.14201/et20143217396

\title{
CRITERIOS PARA LA SELECCIÓN DE IMÁGENES SIN ESTEREOTIPOS VINCULADAS CON LA PRÁCTICA DE ACTIVIDAD FÍSICO-DEPORTIVA EN LA EDICIÓN DE LIBROS DE TEXTO
}

\section{Criteria evaluation for the Selection of Physical activity Images for School Textbooks that are Free of Stereotypes}

\section{Critères d'évaluation pour la sélection d'images de l'activité physique et sportive libres d'stéréotypes dans les livres de texte}

Ana Rey-CaO*, M. ${ }^{a}$ Inés TÁBOAS-PAis** y Alba GonZÁleZ-PALOMARES*

*Universidade de Vigo. Correo-e: anacao@uvigo.es; albagonzalez@uvigo.es

** Universidad Católica San Antonio de Murcia.Correo-e: mtaboas@ucam.edu

Recibido: 04.06.2013; Aceptado: 12.02.2014; Publicado: 31.10.2014

BIBLID [0212-5374 (2014) 32, 2; 73-96]

Ref. Bibl. ANA REY-CAO, M. ํㅗㄴ INÉS TÁBOAS-PAIS y ALBA GONZÁLEZ-PALOMARES. Criterios para la selección de imágenes sin estereotipos vinculadas con la práctica de actividad físico-deportiva en la edición de libros de texto. Enseñanza \& Teaching, 32, 2-2014, 73-96.

RESUMEN: El artículo presenta criterios de evaluación para seleccionar las imágenes vinculadas con la práctica de actividad físico-deportiva en la edición de libros de texto de tal forma que estén libres de estereotipos. Los manuales escolares son portadores de un conocimiento que no siempre guarda una relación unívoca con lo que debe ser enseñado. La selección de sus contenidos debería ser coherente con las finalidades del sistema educativo, pero la investigación revela que la edición 
ANA REY-CAO, M. ํㅗㄴ INÉS TÁBOAS-PAIS Y ALBA GONZÁLEZ-PALOMARES

CRITERIOS PARA LA SELECCIÓN DE IMÁGENES SIN ESTEREOTIPOS VINCULADAS CON LA PRÁCTICA

DE ACTIVIDAD FÍSICO-DEPORTIVA EN LA EDICIÓN DE LIBROS DE TEXTO

de los contenidos visuales no se corresponde con la aplicación de criterios que respondan a esa intencionalidad. Tras una aparente neutralidad, las imágenes de los libros de texto enmascaran prejuicios y reproducen desigualdades que afectan a determinados colectivos frágiles. Los criterios de evaluación para la selección de imágenes que se presentan en este trabajo fueron elaborados de acuerdo con los resultados de una investigación que analizó los estereotipos de género, edad, raza, discapacidad y tipología corporal en las imágenes de manuales escolares de educación física para la ESO en España, así como la percepción del alumnado de secundaria sobre una selección significativa de las mismas imágenes. Los criterios elaborados pueden aplicarse para la selección de fotografías destinadas a manuales de diferentes áreas de conocimiento en las que aparezcan representadas personas vinculadas a la práctica de actividad físico-deportiva. La aplicación de los criterios de evaluación se ejemplifica en la selección de contenidos visuales para un hipotético libro de educación física.

Palabras clave: libro de texto, estereotipo, prejuicio, evaluación, imagen, educación física.

SUMMARY: This article presents a series of evaluation criteria for the selection of physical activity images for school textbooks that are free of stereotypes. School textbooks are purveyors of information that does not always maintain an unequivocal relationship with regards to the knowledge that is supposed to be imparted. The selection of textbook content should be consistent with the goals of the education system but research has shown that the visual content of textbooks does not generally achieve this aim. Images used in textbooks mask prejudices behind a facade of neutrality and they reproduce stereotypes of inequality that affect the most vulnerable societal collectives. Textbook evaluation criteria are based on the results of research that analysed stereotypes in Spanish secondary school textbooks and the perceptions of the secondary school students when shown a significant sample of the images. The evaluation criteria can be applied to the selection of textbook images for the different subject areas, taking into account the variables of sex, age, multiculturality, disability and the corporal typology of the people that are represented. The application of the system is exemplified with the selection of images for a hypothetical physical education textbook.

Key words: texbook, estereotype, prejudice, evaluation, image, physical education.

RÉSUMÉ: L'article présente une série de critères d'évaluation pour la sélection d'images de l'activité physique et sportive librement d'stéréotypes dans les manuels scolaires. Les manuels d'enseignement sont des porteurs d'une connaissance que ne garde pas toujours une relation univoque avec ce que doit être enseigné. La sélection de ses contenus devrait être cohérent avec les finalités du système éducatif, mais la recherche révèle que l'édition des contenus visuels ne se correspond pas avec l'application de critères qu'ils répondent à cette intentionnalité. Après une 
ANA REY-CAO, M. ․ INÉS TÁBOAS-PAIS Y ALBA GONZÁLEZ-PALOMARES

CRITERIOS PARA LA SELECCIÓN DE IMÁGENES SIN ESTEREOTIPOS VINCULADAS CON LA PRÁCTICA

DE ACTIVIDAD FÍSICO-DEPORTIVA EN LA EDICIÓN DE LIBROS DE TEXTO

apparente neutralité, les images des manuels scolaires ils masquent des préjugés et ils reproduisent les inégalités qui affectent les collectifs sociaux les plus vulnérables. Les critères d'évaluation pour la sélection d'images des manuels d'enseignement que se présentent dans ce travail ils ont été élaborés d'accord avec les résultats d'une recherche qu'il a analysé les stéréotypes de genre, âge, race, handicap et typologie corporels dans les images de manuels pour la Éducation Secondaire Obligatoire -ESO- en Espagne, ainsi que les aperçus de l'étudiants de secondaire à ce sujet d'une sélection significative des mêmes images. Les critères d'évaluation élaborés peuvent s'appliquer pour la sélection de photographies destinées à des manuels de différentes zones de connaissance dans lesquelles ils apparaissent des personnes représentées, quant à le variable genre, âge, multiculturalité, handicap et typologie corporels des personnes représentées. L'application des critères d'évaluation s'illustre dans la sélection de contenus visuels pour un hypothétique manuel d'enseignement d'éducation physique.

Mots clés: manuel d'enseignement, stéréotype, préjugé, évaluation, image, éducation physique.

\section{INTRODUCCIÓN}

La calidad de la educación viene determinada por indicadores de funcionalidad, eficacia y eficiencia. La funcionalidad se define como la capacidad de un sistema para ajustar sus objetivos y, a través de ellos, los productos, acciones y medios de que dispone a las funciones que le han sido asignadas por la sociedad (De la Orden, 2009). Los materiales didácticos son portadores de un conocimiento que ha sido transformado con finalidad didáctica, y que no siempre guarda una relación unívoca con el conocimiento que debe ser enseñado (Ruiz y Camps, 2009), por ello es necesario evaluarlos para que sean funcionales. De la Orden (2009) señala que, a pesar de la falta de acuerdo sobre las metas educativas deseables, es posible identificar índices para determinar la funcionalidad del sistema educativo. Entre ellos se encuentra la relación entre los inputs o entradas al sistema educativo y los valores sociales. Los libros de texto son inputs al sistema educativo y, por tanto, deben ser productores de saberes, valores y modos de actuar coherentes con las finalidades del sistema educativo y con el contexto jurídico español -de modo especial con la Ley Orgánica 1/2004, de 28 de diciembre, de Medidas de Protección Integral contra la Violencia de Género; la Ley Orgánica 3/2007, de 22 de marzo, para la igualdad efectiva de mujeres y hombres; la Convención Internacional sobre los Derechos de las Personas con Discapacidad y la Ley 26/2011, de 1 de agosto, de adaptación normativa a la Convención Internacional sobre los Derechos de las Personas con Discapacidad-. Este conjunto legislativo ampara la supresión de cualquier prejuicio por cuestiones de género, edad, discapacidad, origen, características étnicas y/o culturales, condición sexual, creencias religiosas o morfología corporal. 
ANA REY-CAO, M.ํㅗNÉS TÁBOAS-PAIS Y ALBA GONZÁLEZ-PALOMARES

CRITERIOS PARA LA SELECCIÓN DE IMÁGENES SIN ESTEREOTIPOS VINCULADAS CON LA PRÁCTICA DE ACTIVIDAD FÍSICO-DEPORTIVA EN LA EDICIÓN DE LIBROS DE TEXTO

El estado de estas variables en la sociedad no es "neutro", sino que complejas configuraciones sociohistóricas penalizan a determinados colectivos. Si los libros de texto se limitan a representar lo que existe, estarán contribuyendo a reproducir las desigualdades vigentes con respecto a estos colectivos frágiles (Atienza, 2007; Moeglin, 2005). Los imaginarios sociales presentes en los textos escolares reducen la complejidad propia de la realidad social al proporcionar un esquema de distinción que ordena, explica y permite intervenir en lo que se configura como real (Jorquera, 2011). La intencionalidad debe guiar la selección de contenidos de los libros de texto -incluidos los contenidos visuales, imágenes fotográficas o ilustraciones- para modular funcionalmente el imaginario social al que contribuye. Por ejemplo, si la lógica adoptada para la selección de contenidos visuales fuese la reproducción o la correspondencia con datos empíricos, las personas con discapacidad deberían estar representadas en un 8,5\% de las imágenes de los libros de texto, porcentaje acorde a la tasa de presencia de este colectivo en España (INE, 2009). Pero la presencia de personas con discapacidad debería ser manifiestamente mayor para trasladar un mensaje acorde a la finalidad de inclusión de este colectivo. En este sentido, el concepto de discriminación positiva podría trasladarse a los materiales curriculares como el de "representación positiva". Una presencia intencionadamente mayor que la real para aquellos colectivos que, dañados por prejuicios, requieren de la producción de un nuevo imaginario que incremente su presencia y vinculación con acciones silenciadas hasta el momento.

El lenguaje icónico está muy presente en los libros de texto y es un poderoso medio para la reproducción de estereotipos. Un elevado porcentaje de la información que llega a los jóvenes lo hace a través de las imágenes y se filtra en la conciencia sin una reflexión previa (Acaso y Nuere, 2005). El efecto que el mensaje icónico de una fotografía causa en el receptor se incrementa porque dicho mensaje se percibe como un reflejo objetivo de la realidad. Esta equiparación mensaje-realidad ocurre de forma especial con las fotografías. Especialmente entre los 12 y 15 años existe una tendencia a legitimar la identidad a través de la imagen, percibiéndola como "realidad innegable" (Revuelta, 2008). Del mismo modo la cultura icónica ocupa un puesto muy relevante en la constitución de concepciones y perspectivas del profesorado, por lo que es urgente diseñar estrategias que incrementen la conciencia sobre el poder que tienen los medios audiovisuales (Giner, Martínez y Sauleda, 2009).

\section{Prejuicios Vinculados a la CUltura corporal EN los libros de teXTO}

Los datos de diversas investigaciones en los contextos nacional e internacional indican que los prejuicios están presentes en los manuales escolares de múltiples materias (véase, por ejemplo, Goldstein, Siegel y Seaman, 2009; Knudsen, 2005; Lee y Collins, 2008; Luengo y Blázquez, 2004; Morales y Lischinsky, 2008; Sleeter y Grant, 2011). Pilar Colás (1989) apuntaba, ya en la década de los 90, la necesidad 
CRITERIOS PARA LA SELECCIÓN DE IMÁGENES SIN ESTEREOTIPOS VINCULADAS CON LA PRÁCTICA DE ACTIVIDAD FÍSICO-DEPORTIVA EN LA EDICIÓN DE LIBROS DE TEXTO

de que los resultados de las investigaciones sobre libros de texto e ilustraciones sirviesen para orientar la forma en que estos materiales deben ser estructurados.

Los criterios de evaluación que se presentan en este trabajo permitieron adaptar al campo de la cultura corporal los criterios explicitados por la UNESCO (2005). La cultura corporal puede conceptualizarse como el conjunto de valores, usos, saberes, creencias, normas y pautas de conducta que delimitan las apreciaciones y prácticas corporales en un determinado contexto social (GonzálezPalomares y Rey-Cao, 2013). El campo de las actividades físico-deportivas es un espacio social que maneja una serie de elementos vinculados con las prácticas corporales, y por extensión con algunas dimensiones de la cultura corporal. Este concepto aglutina toda una variedad de prácticas vinculadas con la motricidad intencional, que no tienen cabida en la concepción tradicional del vocablo deporte. Por ejemplo, actividades motrices con mujeres gestantes, personas con sobrepeso o personas mayores; prácticas corporales como pasear, andar en bicicleta, etc.; que son diferentes a los deportes estandarizados, competitivos e institucionalizados en federaciones.

Los criterios fueron elaborados en base a los resultados de una investigación que analizó las imágenes publicadas en libros de texto de educación física -EF(Táboas, 2009; Táboas y Rey, 2011a, 2011b, 2012; Táboas-Pais y Rey-Cao, 2012a, 2012b; Rey-Cao, Táboas-Pais y Canales-Lacruz, 2013). El total de imágenes analizadas en estos estudios fue de 3.316, extraídas de 36 libros de texto publicados por las 10 editoriales que durante los años 2000 y 2006 editaron manuales de EF para los cuatro cursos que configuran la ESO. Se realizó un estudio empírico, descriptivo y seccional mediante el análisis de contenido de las imágenes fotográficas de los libros de texto. Se utilizó el sistema de categorías que puede consultarse en la Tabla 1.

TABLA 1

Estructura del sistema de categorías empleado en el análisis de las imágenes

\begin{tabular}{|l|l|l|}
\hline \multicolumn{1}{|c|}{ DIMENSIONES } & \multicolumn{1}{|c|}{ CATEGORÍAS } & \multicolumn{1}{c|}{ INDICADORES } \\
\hline \multirow{2}{*}{ CARACTERÍSTICAS TÉCNICAS } & Tipo de plano & $\begin{array}{l}\text { Plano general } \\
\text { Plano de conjunto } \\
\text { Plano entero } \\
\text { Plano americano o tres cuartos } \\
\text { Plano medio } \\
\text { Primer plano } \\
\text { Plano detalle }\end{array}$ \\
\cline { 2 - 3 } & Tipo de enfoque & $\begin{array}{l}\text { Picado } \\
\text { Contrapicado } \\
\text { Medio }\end{array}$ \\
\hline
\end{tabular}


ANA REY-CAO, M. ํㅗㄴ INÉS TÁBOAS-PAIS Y ALBA GONZÁLEZ-PALOMARES

CRITERIOS PARA LA SELECCIÓN DE IMÁGENES SIN ESTEREOTIPOS VINCULADAS CON LA PRÁCTICA DE ACTIVIDAD FÍSICO-DEPORTIVA EN LA EDICIÓN DE LIBROS DE TEXTO

\begin{tabular}{|c|c|c|}
\hline DIMENSIONES & CATEGORÍAS & INDICADORES \\
\hline \multirow{34}{*}{ 1. CUERPO } & \multirow{6}{*}{$\begin{array}{l}\text { 1.1. Sexo- } \\
\text { agrupación }\end{array}$} & 1.1.1. Hombre \\
\hline & & 1.1.2. Mujer \\
\hline & & 1.1.3. Grupo de hombres \\
\hline & & 1.1.4. Grupo de mujeres \\
\hline & & 1.1.5. Grupo de hombres-mujeres \\
\hline & & 1.1.6. No se distingue \\
\hline & \multirow{6}{*}{ 1.2. Edad } & 1.2.1. Niño/Adolescente \\
\hline & & 1.2.2. Joven \\
\hline & & 1.2.3. Adulto \\
\hline & & 1.2.4. Persona mayor \\
\hline & & 1.2.5. Varios \\
\hline & & 1.2.6. No se distingue \\
\hline & \multirow{8}{*}{ 1.3. Raza } & 1.3.1. Blanca \\
\hline & & 1.3.2. Negra \\
\hline & & 1.3.3. Asiática \\
\hline & & 1.3.4. Indígena latinoamericana \\
\hline & & 1.3.5. Semita \\
\hline & & 1.3.6. Otras \\
\hline & & 1.3.7. Varios \\
\hline & & 1.3.8. No se distingue \\
\hline & \multirow{6}{*}{ 1.4. Somatotipo } & 1.4.1. Mesomorfo \\
\hline & & 1.4.2. Endomorfo \\
\hline & & 1.4.3. Ectomorfo \\
\hline & & 1.4.4. Combinación \\
\hline & & 1.4.5. Varios \\
\hline & & 1.4.6. No se distingue \\
\hline & \multirow{8}{*}{ 1.5. Indumentaria } & 1.5.1. Desnudo/a \\
\hline & & 1.5.2. Desnudo/a torso \\
\hline & & 1.5.3. Ropa de deporte \\
\hline & & 1.5.4. Ropa interior \\
\hline & & 1.5.5. Ropa de trabajo \\
\hline & & 1.5.6. Ropa de calle \\
\hline & & 1.5.7. Varios \\
\hline & & 1.5.8. No se distingue \\
\hline
\end{tabular}


ANA REY-CAO, M. ํㅗㄴ INÉS TÁBOAS-PAIS Y ALBA GONZÁLEZ-PALOMARES

CRITERIOS PARA LA SELECCIÓN DE IMÁGENES SIN ESTEREOTIPOS VINCULADAS CON LA PRÁCTICA DE ACTIVIDAD FÍSICO-DEPORTIVA EN LA EDICIÓN DE LIBROS DE TEXTO

\begin{tabular}{|c|c|c|}
\hline DIMENSIONES & CATEGORÍAS & INDICADORES \\
\hline \multirow{28}{*}{ 2. ACTIVIDAD FÍSICO-DEPORTIVA } & \multirow{14}{*}{ 2.1. Tipo } & 2.1.1. Deportes colectivos \\
\hline & & 2.1.2. Deportes individuales \\
\hline & & 2.1.3. Artísticas \\
\hline & & 2.1.4. Fitness y Condición Física \\
\hline & & 2.1.5. Complementarias \\
\hline & & 2.1.6. De higiene postural \\
\hline & & 2.1.7. AFAN \\
\hline & & 2.1.8. Prácticas de interiorización \\
\hline & & 2.1.9. Juegos \\
\hline & & 2.1.10. Laborales \\
\hline & & 2.1.11. AVD \\
\hline & & 2.1.12. Adaptadas \\
\hline & & 2.1.13. Otras \\
\hline & & 2.1.14. No se distingue \\
\hline & \multirow{5}{*}{$\begin{array}{l}\text { 2.2. Ámbito de } \\
\text { práctica }\end{array}$} & 2.2.1. Competitivo \\
\hline & & 2.2.2. Educativo formal \\
\hline & & 2.2.3. Utilitario \\
\hline & & 2.2.4. Otros \\
\hline & & 2.2.5. No se distingue \\
\hline & \multirow{6}{*}{ 2.3. Espacio } & 2.3.1. Exterior deportivo \\
\hline & & 2.3.2. Medio natural \\
\hline & & 2.3.3. Exterior \\
\hline & & 2.3.4. Interior deportivo \\
\hline & & 2.3.5. Interior \\
\hline & & 2.3.6. No se distingue \\
\hline & \multirow{3}{*}{ 2.4. Nivel } & 2.4.1. Élite \\
\hline & & 2.4.2. No élite \\
\hline & & 2.4.3. No se distingue \\
\hline
\end{tabular}

La función referencial de la fotografía es lo que interesa para esta investigación, de ahí que el sistema de categorías empleado se preocupe por identificar "indicadores" observables que puedan suscitar la percepción de la diferencia. El sistema de análisis empleado en la presente investigación no debe contemplarse como una clasificación teórica al respecto de los distintos fenómenos que configuran las categorías, sino simplemente como una herramienta para identificar en las fotografías indicadores observables que actúan como referentes "semióticomateriales" en la conciencia de las personas que las observan y las llevan a un proceso de formación de subjetividades en torno a los indicadores. Al respecto, las autoras son conscientes de las limitaciones del uso del concepto "raza", ya que tanto en su construcción biologicista como culturalista el término constituye una 
ANA REY-CAO, M. ․ INÉS TÁBOAS-PAIS Y ALBA GONZÁLEZ-PALOMARES

CRITERIOS PARA LA SELECCIÓN DE IMÁGENES SIN ESTEREOTIPOS VINCULADAS CON LA PRÁCTICA DE ACTIVIDAD FÍSICO-DEPORTIVA EN LA EDICIÓN DE LIBROS DE TEXTO

ficción reguladora, mediante el que determinadas diferencias se transforman en significativas, legitimando opresiones y exclusiones; privilegios y dominaciones (Romero, 2003).

El sistema fue validado mediante consulta a expertos/as y dos pruebas piloto. La fiabilidad se determinó mediante el estadístico kappa de Cohen $(>0,80)$ aplicado a la triangulación entre tres codificadores que analizaron 74 imágenes y un análisis entre codificadores a partir de un $10 \%$ de la muestra final del estudio. Se empleó el programa SPSS 15.0 para realizar un análisis descriptivo univariante y medidas asociativas entre las diferentes variables -análisis bivariante-. Se utilizaron tablas de contingencia para comparar las frecuencias observadas y los porcentajes. La prueba Chi-cuadrado de Pearson $\left(\chi^{2}\right)$ se aplicó para contrastar las hipótesis nulas (H0), en las que se establece que las dos variables cruzadas son independientes. En este trabajo, el estadístico Chi-cuadrado para contrastar la significatividad de cada una de las correlaciones propuestas se obtuvo tomando un nivel de significación $=0,05$.

También se recogieron datos de una prueba de percepción que se realizó con alumnado de secundaria. Su finalidad era comprobar si las imágenes fotográficas de los libros de texto de EF promovían la reproducción de una cultura corporal estereotipada (Táboas y Rey, 2011a). La prueba se aplicó en cuatro grupos, uno de cada curso de la ESO. La muestra fue de 87 estudiantes -45 mujeres y 42 hombrescon edades comprendidas entre 12 y 17 años. Se proyectaron quince imágenes seleccionadas de los libros de texto de EF. Su elección se basó en la presencia de modelos corporales y de actividad física que son comunes en los libros de texto de EF y que habían sido identificados en los estudios previos. El estudio de las descripciones del alumnado se realizó mediante análisis de contenido. Se empleó el programa de análisis cualitativo N-VIVO 8.

Los resultados revelaron la existencia de una serie de estereotipos vinculados a la práctica de actividad físico-deportiva que prevalecen en los libros de texto y que desplazan a determinados colectivos por razones de género, edad, aspectos étnico-culturales o discapacidad. Estos estereotipos se manifiestan especialmente en la exaltación de lo masculino frente a lo femenino, la entronización de la juventud y el rechazo a la imagen de la vejez, la invisibilización de los exogrupos -personas diferentes al modelo etnocéntrico europeo- y la omisión de las personas con discapacidad.

Las mujeres son excluidas de los espacios exteriores y vinculadas a actividades físico-deportivas que responden al patrón hegemónico de la feminidad. Se perpetúa una atribución de actividades físicas "para hombres" y actividades físicas "para mujeres", la caracterización de la competición y el alto rendimiento como cotos masculinos, la diferenciación entre espacios públicos masculinos y espacios privados femeninos, la transmisión de la cultura del músculo y la cultura de la delgadez, y la exaltación de la mujer como objeto de seducción (Táboas-Pais y Rey-Cao, 2012a). 
ANA REY-CAO, M.ํㅗㅌÉS TÁBOAS-PAIS Y ALBA GONZÁLEZ-PALOMARES

CRITERIOS PARA LA SELECCIÓN DE IMÁGENES SIN ESTEREOTIPOS VINCULADAS CON LA PRÁCTICA DE ACTIVIDAD FÍSICO-DEPORTIVA EN LA EDICIÓN DE LIBROS DE TEXTO

La representación de las personas mayores está polarizada entre una visión idílica y una visión pasiva del envejecimiento. La escasa visibilidad de las personas mayores se hace más evidente cuando se trata de mujeres mayores o de personas de razas diferentes a la blanca. Las actividades físicas en las que participan son limitadas: principalmente juegos tradicionales y deportes individuales (Rey-Cao, Táboas-Pais y Canales-Lacruz, 2013).

Las personas con apariencia diferente al endogrupo participan en un escaso número de actividades físico-deportivas -fundamentalmente atletismo y baloncesto- y en contextos -competición y alto rendimiento- que responden a los estereotipos vigentes sobre determinados colectivos étnico-culturales (González, Táboas y Rey, 2010).

Las personas con discapacidad son representadas mediante atributos estereotipados que omiten su diversidad o legitiman su visibilización mediante la adecuación a los patrones hegemónicos del éxito y la eficacia motriz (Táboas-Pais y Rey-Cao, 2012b).

Con relación a la estructuración de los contenidos del área de EF existe una desproporción entre los diferentes bloques de contenidos. Se priman el deporte y el ejercicio físico, y se relega a posiciones marginales el resto de actividades físicodeportivas: actividades en el medio natural, actividades artísticas y de expresión corporal, prácticas de interiorización o ejercicios de higiene postural. Además se exalta la competición institucionalizada y el elitismo motriz.

Los criterios de evaluación anexos sirven de referente para todos los manuales escolares donde aparezcan representadas imágenes vinculadas con la cultura corporal y la práctica de actividad físico-deportiva.

La intención de los criterios de evaluación es facilitar la edición de materiales didácticos de calidad y la reflexión por parte de los profesionales que hacen uso de estos materiales. No han sido concebidos para aplicarse mecánicamente, sino como criterios reflexivo-comprensivos.

\section{CRITERIOS PARA LA SELECCIÓN DE IMÁGENES VINCULADAS CON LA CULTURA CORPORAL Y LA ACTIVIDAD FÍSICO-DEPORTIVA EN LA EDICIÓN DE LIBROS DE TEXTO}

Es recomendable que las imágenes vinculadas a la cultura corporal que aparecen en los libros de texto de educación secundaria:

- Representen la diversidad e idiosincrasia característica de la sociedad contemporánea.

- Eviten la reproducción de estereotipos que puedan ocasionar prejuicios a determinados colectivos.

- Muestren la diversidad de actividades físico-deportivas que forman parte de la cultura corporal, evitando privilegiar aquellas que tienen más difusión popular, mediática y/o mercantilista. 
ANA REY-CAO, M.ํㅗNÉS TÁBOAS-PAIS Y ALBA GONZÁLEZ-PALOMARES

CRITERIOS PARA LA SELECCIÓN DE IMÁGENES SIN ESTEREOTIPOS VINCULADAS CON LA PRÁCTICA DE ACTIVIDAD FÍSICO-DEPORTIVA EN LA EDICIÓN DE LIBROS DE TEXTO

Para hacer efectivos estos criterios generales se proponen los siguientes criterios específicos.

\subsection{Representación de hombres y mujeres}

Compartida, equilibrada e igualitaria.

Evitar la representación de la mujer asociada mayoritariamente al patrón hegemónico femenino: doméstica, seductora, delicada, frágil y maternal.

Evitar la representación del hombre asociado mayoritariamente al patrón hegemónico masculino: intrépido, activo, resuelto, fuerte y seguro.

Equilibrar el porcentaje de imágenes en las que aparecen solo hombres y en las que aparecen solo mujeres.

Incorporar preferentemente imágenes donde figuren hombres y mujeres compartiendo actividades físico-deportivas similares, en lugar de aquellas en las que aparecen solo hombres o solo mujeres.

Representar equitativamente a hombres y mujeres en imágenes vinculadas con los diferentes espacios -exteriores e interiores-, ámbitos -educativos, instrumentales, escénicos, informales, utilitarios- y contenidos curriculares. Evitar la representación de una participación mayoritaria de hombres en actividades físicas en el medio natural, juegos, actividades de tipo laboral o deportes -entendidos como actividades ligadas a la competición, la reglamentación, la institucionalización y el rendimiento-, y una participación mayoritaria de mujeres en actividades artísticas, actividades del mundo del fitness o prácticas de interiorización y actividades de la vida diaria -domésticas-.

Representar la participación de hombres y mujeres en competición institucionalizada y en la élite o alto rendimiento en una proporción similar.

\subsection{Representación de los diferentes grupos de edad}

Diversa, equilibrada e intergeneracional.

Seleccionar imágenes que incorporen a personas de diferentes franjas etarias.

Evitar la representación excesiva de una franja etaria asociada a una determinada actividad físico-deportiva, ámbito o espacio.

Incorporar imágenes de personas adultas y personas mayores de ambos géneros participando en una amplia variedad de actividades físico-deportivas. Evitar limitar su representación asociada a la práctica de actividades de la vida diaria o a juegos tradicionales.

Evitar la invisibilización y estereotipación de las personas mayores, especialmente de las mujeres mayores. Mostrar diversidad de morfologías corporales y evitar las representaciones ejemplares polarizadas - entre personas mayores «juveniles y hedonistas" o "fragilizadas y dependientes"-, ya que pueden legitimarse como los únicos roles en los que las personas mayores merecen ser visibilizadas socialmente. Representar a personas mayores y adultas con vestimentas que rehúyan la construcción de tópicos en torno al envejecimiento. 
ANA REY-CAO, M.ํㅗNÉS TÁBOAS-PAIS Y ALBA GONZÁLEZ-PALOMARES

CRITERIOS PARA LA SELECCIÓN DE IMÁGENES SIN ESTEREOTIPOS VINCULADAS CON LA PRÁCTICA DE ACTIVIDAD FÍSICO-DEPORTIVA EN LA EDICIÓN DE LIBROS DE TEXTO

Privilegiar la representación del contacto intergeneracional, especialmente en imágenes en las que las personas mayores participen conjuntamente con personas de otras franjas etarias.

\subsection{Representación de la diversidad étnica y cultural}

Plural, idiosincrática e inclusiva.

Visibilizar la multiculturalidad. Combinar las imágenes de personas cuya apariencia corresponde al modelo etnocéntrico europeo con imágenes de personas de diferentes orígenes y características étnico-culturales.

Representar la inclusión de personas de diversidad étnico-cultural en todo el abanico de expresiones motrices -juegos, deportes, ejercicio físico, actividades artísticas, prácticas de interiorización-, en todos los ámbitos -competitivo, educativo, instrumental, escénico, informal, utilitario- y niveles -élite, no élite-.

Evitar significar la diferencia mediante estereotipos populistas. Evitar que la mayoría de las imágenes correspondientes a personas de apariencia diferente al endogrupo se vinculen con el deporte competitivo y/o de élite. Evitar la representación de personas negras vinculadas exclusivamente a las modalidades deportivas de baloncesto, atletismo o boxeo.

Privilegiar la representación de la inclusión. Mostrar imágenes en las que las personas convivan en una ciudadanía multicultural. Evitar la representación de la multiculturalidad mediante el uso mayoritario de imágenes que representen a exogrupos sin interrelación con el endogrupo.

\subsection{Representación de la discapacidad}

Plural, contrastada e inclusiva.

Visibilizar la discapacidad. Combinar imágenes que incluyen a personas sin discapacidad con imágenes que incluyen a personas con discapacidad. Representar la inclusión de personas con discapacidad en todo el abanico de expresiones motrices -juegos, deportes, ejercicio físico, actividades artísticas, prácticas de interiorización-, en todos los ámbitos -competitivo, educativo, instrumental, escénico, informal, utilitario-y niveles -élite, no élite-.

Privilegiar la representación de la inclusión. Seleccionar imágenes en las que personas con discapacidad participen conjuntamente con personas sin discapacidad.

Mostrar diversidad de discapacidades y de deficiencias que la originan: osteoarticulares, auditivas, visuales, mentales, lingüístico-comunicativas, etc. Cuando esta representación no pueda significarse a través de la imagen, sería recomendable incorporar información alusiva en los paratextos.

Evitar la estereotipación y la estigmatización. Evitar la representación de la silla de ruedas como símbolo exclusivo de la discapacidad. Las imágenes que muestren a personas con discapacidad deben mostrar su participación en actividades, ámbitos y espacios diversos. 
ANA REY-CAO, M.ํㅗ INÉS TÁBOAS-PAIS Y ALBA GONZÁLEZ-PALOMARES

CRITERIOS PARA LA SELECCIÓN DE IMÁGENES SIN ESTEREOTIPOS VINCULADAS CON LA PRÁCTICA DE ACTIVIDAD FÍSICO-DEPORTIVA EN LA EDICIÓN DE LIBROS DE TEXTO

Evitar que la mayoría de las imágenes en las que aparecen personas con discapacidad estén vinculadas con su participación en deporte competitivo y/o de élite, interviniendo de forma segregada en actividades físicas adaptadas o siendo asistidas. Incorporar imágenes donde se represente su participación en contextos educativos y recreativos.

Evitar la representación recurrente de la persona discapacitada "extraordinaria" como única vía para lograr su visibilización social. Evitar que la discapacidad se muestre casi exclusivamente asociada a la realización de hazañas deportivas de elevada eficacia motriz ${ }^{1}$, ya que pueden legitimarse como los únicos roles en los que las personas con discapacidad merecen ser visibilizadas socialmente.

\subsection{Representación de la tipología somática de las personas}

Diversa, respetuosa y no tendenciosa.

Mostrar a personas de distintas morfologías corporales: endomórfica -gruesa, de formas suaves y redondeadas-; ectomórfica -delgada, de formas largas y líneales-; mesomórfica -atlética y musculada-, y sus múltiples combinaciones.

Incorporar a personas de diferentes morfologías corporales participando en todo el abanico de actividades físico-deportivas, ámbitos y espacios que se muestran en el libro de texto.

Evitar la excesiva representación de personas vinculadas a la práctica de actividad físico-deportiva cuya morfología se corresponde a los ideales estéticos hegemónicos. En el caso del hombre, morfología mesomórfica -cuerpo atlético, musculado- y en el caso de la mujer, morfología ectomórfica -cuerpo frágil, delgado y ligeramente musculado-.

\subsection{Representación de los contenidos de la educación física}

Representar de forma equilibrada la diversidad de actividades físico-deportivas presentes en la cultura corporal y que responden a la contribución de la materia a la adquisición de las competencias básicas, a los objetivos generales del área, a los contenidos y a los criterios de evaluación establecidos en el Real Decreto 1631/2006 por el que se establecen las enseñanzas mínimas correspondientes a la ESO. Entre ellas se mencionan específicamente el ejercicio físico -incluidas las técnicas básicas de corrección postural-, los juegos, los deportes individuales y colectivos, diferentes técnicas para el desarrollo de la expresión corporal -incluidas las técnicas de respiración, relajación, bailes y danzas- y las actividades en el medio natural.

1. Las prácticas deportivas propician una domesticación del cuerpo discapacitado a partir de un intento de acercamiento al cuerpo capaz/normal, intensificando los procesos de exclusión asociados a la discapacidad (Ferrante, 2010). 
ANA REY-CAO, M.ํㅗNÉS TÁBOAS-PAIS Y ALBA GONZÁLEZ-PALOMARES

CRITERIOS PARA LA SELECCIÓN DE IMÁGENES SIN ESTEREOTIPOS VINCULADAS CON LA PRÁCTICA

DE ACTIVIDAD FÍSICO-DEPORTIVA EN LA EDICIÓN DE LIBROS DE TEXTO

Evitar la transmisión mayoritaria de las expresiones motrices hegemónicas -deporte de competición y élite; ejercicio físico instrumentalizado al servicio de la "cultura de la forma"-. Equilibrar los porcentajes de imágenes que representen contenidos de deportes y condición física con los vinculados a los bloques de contenidos de expresión corporal y actividades físicas en el medio natural.

Mostrar modelos de vivencia corporal al alcance de los diferentes sectores de la población: juegos tradicionales, actividades introspectivas, senderismo, paseos en bicicleta, etc.

4. EJEMPlo de la APLICACIÓN DE lOS CRITERIOS DE EVALUACIÓN EN LA SELECCIÓN DE IMÁGENES DE UN LIBRO DE TEXTO

Esta propuesta está realizada para un hipotético libro de EF con 100 fotografías como ejemplificación de la funcionalidad de estos criterios para la selección de las imágenes.

\subsection{Proceso de elaboración}

La elaboración de la propuesta se estructuró en dos grandes etapas. En la primera se distribuyeron las imágenes en función de los contenidos que deben representar los libros de texto de EF. Las variables incluidas para caracterizar los contenidos fueron las propuestas por Táboas y Rey (2012): el tipo de actividad, el ámbito, el nivel de práctica y el espacio de práctica.

Se distribuyeron equitativamente los tipos de actividad física representados en las imágenes en correspondencia a los cuatro bloques de contenidos del currículum de EF: 24 imágenes de juegos y deportes-incluyendo deportes colectivos, deportes individuales y juegos-; 24 imágenes de condición física y salud-incluyendo actividades de fitness, ejercicios de condición física y actividades complementarias como la toma de pulsaciones y ejercicios de higiene postural-; 24 imágenes de actividades físicas en el medio natural, y 24 imágenes de expresión corporal -incluyendo actividades artísticas y prácticas de interiorización-. Las 4 imágenes restantes se reservaron para la representación de la motricidad cotidiana-actividades laborales y actividades de la vida diaria-.

La atribución del ámbito se realizó de modo que:

- En los ámbitos educativo e informal estuviesen representados todos los tipos de actividades físicas en un porcentaje similar, ya que son contextos que deben caracterizarse por la diversidad de manifestaciones de la cultura corporal;

- en el ámbito competitivo estuviesen solo representadas, y en un porcentaje similar, las actividades físicas en el medio natural y los deportes, ya que son los únicos susceptibles de realizarse en este ámbito;

- $\quad$ en el ámbito instrumental estuviesen representadas solo las actividades de condición física y en el ámbito escénico sólo las actividades artísticas, 

DE ACTIVIDAD FÍSICO-DEPORTIVA EN LA EDICIÓN DE LIBROS DE TEXTO

ya que son los únicos tipos de expresiones motrices susceptibles de contextualizarse en esos ámbitos.

El nivel se distribuyó de tal modo que en las imágenes caracterizadas como contextos competitivos y escénicos hubiese igual número de casos para la élite y la no élite.

La variable espacio se asignó a todas las imágenes de tal modo que hubiese una distribución equitativa de espacio exterior o espacio interior.

La segunda etapa consistió en la distribución de las características de las personas en las imágenes correspondientes a los diferentes contenidos. Se buscó que todas las posibles combinaciones de estas variables apareciesen representadas en todos los modelos de actividad física que se crearon en la fase anterior: el género -hombres, mujeres o grupos mixtos-, la edad -niños/as y adolescentes, jóvenes y adultos, o personas mayores-, la etnia-cultura -blanca, otras, multicultural, etc.- y la discapacidad.

El resultado de la matriz con las características de las 100 imágenes fue exportada al programa estadístico spss 19.0 para analizar si la propuesta superaba los estereotipos detectados en la investigación previa. Se realizó un análisis descriptivo univariante y medidas de asociación entre las diferentes variables o categorías -bivariante-. Se emplearon tablas de contingencia, frecuencias observadas y porcentajes; y se utilizó el test Chi-cuadrado de Pearson -prueba de independenciapara identificar asociaciones entre las variables, fijando el nivel de significación estadística en el 5\% $(\alpha=.05)$.

El análisis de los gráficos solicitados de frecuencias y porcentajes arrojó como resultado que la distribución de actividades y de personas no respondía a modelos desequilibrados a favor de lo deportivo, lo competitivo, lo masculino, lo joven, del etnocentrismo europeo o de la invisibilización de la discapacidad. La prueba Chi-cuadrado de Pearson reveló que para todas las posibles asociaciones entre variables el valor crítico asociado al estadístico $\chi^{2}$ era inferior a $.05(\mathrm{p}=.000)$. Esto significa que las variables son independientes, y que las personas representadas en las fotografías no se vinculan a unas u otras actividades en función de su género, su edad, su aspecto étnico-cultural o la presencia de alguna discapacidad. 
ANA REY-CAO, M. ․ INÉS TÁBOAS-PAIS Y ALBA GONZÁLEZ-PALOMARES

CRITERIOS PARA LA SELECCIÓN DE IMÁGENES SIN ESTEREOTIPOS VINCULADAS CON LA PRÁCTICA

DE ACTIVIDAD FÍSICO-DEPORTIVA EN LA EDICIÓN DE LIBROS DE TEXTO

\subsection{Resultado}

El resultado de la propuesta se muestra en la Tabla 2.

TABLA 2

Selección de imágenes para un hipotético libro de EF con 100 imágenes

\begin{tabular}{|c|c|c|c|c|c|c|c|c|}
\hline $\begin{array}{c}\text { TIPO } \\
\text { ACTIVIDAD } \\
\text { FÍSICA } \\
\end{array}$ & N. $\stackrel{\circ}{ }$ & ÁмBITO & NIVEL & ESPACIO & GÉNERO & EDAD & $\begin{array}{l}\text { ETNIA- } \\
\text { CULTURA }\end{array}$ & DISCPACIDAD \\
\hline \multirow{8}{*}{ 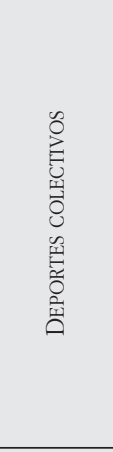 } & 1 & Educativo & No élite & Interior & \begin{tabular}{|l} 
Grupo \\
mixto
\end{tabular} & Niñez/adolescencia & Blanca & Disc. \\
\hline & 2 & Educativo & No élite & Exterior & \begin{tabular}{|l|} 
Grupo \\
mixto
\end{tabular} & Persona mayor & Blanca & Sin \\
\hline & 3 & Competitivo & Élite & Interior & Mujer & Joven/adulto & Blanca & Disc. \\
\hline & 4 & Competitivo & Élite & Exterior & Hombre & Joven/adulto & Blanca & $\operatorname{Sin}$ \\
\hline & 5 & Competitivo & No élite & Interior & Hombre & Niñez/adolescencia & Blanca & $\operatorname{Sin}$ \\
\hline & 6 & Competitivo & No élite & Exterior & Mujer & Niñez/adolescencia & Blanca & $\operatorname{Sin}$ \\
\hline & 7 & Informal & No élite & Interior & $\begin{array}{l}\text { Grupo } \\
\text { mixto }\end{array}$ & Niñez/adolescencia & Otras & $\operatorname{Sin}$ \\
\hline & 8 & Informal & No élite & Exterior & $\begin{array}{l}\text { Grupo } \\
\text { mixto }\end{array}$ & Persona mayor & Blanca & Sin \\
\hline \multirow{8}{*}{ 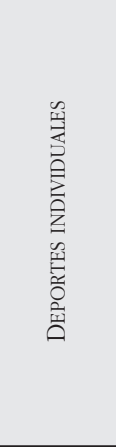 } & 9 & Educativo & No élite & Interior & $\begin{array}{l}\text { Grupo } \\
\text { mixto }\end{array}$ & Persona mayor & Blanca & Sin \\
\hline & 10 & Educativo & No élite & Exterior & \begin{tabular}{|l}
$\begin{array}{l}\text { Grupo } \\
\text { mixto }\end{array}$ \\
\end{tabular} & Niñez/adolescencia & Multicultural & $\operatorname{Sin}$ \\
\hline & 11 & Competitivo & Élite & Interior & Hombre & Joven/adulto & Blanca & Sin \\
\hline & 12 & Competitivo & Élite & Exterior & Mujer & Joven/adulto & Otras & Sin \\
\hline & 13 & Competitivo & No élite & Interior & Mujer & Niñez/adolescencia & Blanca & Sin \\
\hline & 14 & Competitivo & No élite & Exterior & Hombre & Niñez/adolescencia & Blanca & Disc. \\
\hline & 15 & Informal & No élite & Interior & $\begin{array}{l}\text { Grupo } \\
\text { mixto }\end{array}$ & Persona mayor & Blanca & $\operatorname{Sin}$ \\
\hline & 16 & Informal & No élite & Exterior & $\begin{array}{l}\text { Grupo } \\
\text { mixto }\end{array}$ & Niñez/adolescencia & Blanca & $\operatorname{Sin}$ \\
\hline \multirow{8}{*}{$\begin{array}{l}0 \\
\text { 足 } \\
\text { 总 }\end{array}$} & 17 & Educativo & No élite & Interior & Mujer & Joven/adulto & Blanca & Sin \\
\hline & 18 & Educativo & No élite & Interior & Hombre & Niñez/adolescencia & Blanca & Disc. \\
\hline & 19 & Educativo & No élite & Exterior & $\begin{array}{l}\text { Grupo } \\
\text { mixto }\end{array}$ & Niñez/adolescencia & Multicultural & $\operatorname{Sin}$ \\
\hline & 20 & Educativo & No élite & Exterior & $\begin{array}{l}\text { Grupo } \\
\text { mixto }\end{array}$ & Persona mayor & Blanca & Disc. \\
\hline & 21 & Informal & No élite & Interior & $\begin{array}{l}\text { Grupo } \\
\text { mixto }\end{array}$ & Niñez/adolescencia & Blanca & $\operatorname{Sin}$ \\
\hline & 22 & Informal & No élite & Interior & $\begin{array}{l}\text { Grupo } \\
\text { mixto }\end{array}$ & Persona mayor & Blanca & $\operatorname{Sin}$ \\
\hline & 23 & Informal & No élite & Exterior & Mujer & Niñez/adolescencia & Blanca & Disc. \\
\hline & 24 & Informal & No élite & Exterior & Hombre & Joven/adulto & Multicultural & $\operatorname{Sin}$ \\
\hline
\end{tabular}


ANA REY-CAO, M. ํㅗㄹ INÉS TÁBOAS-PAIS Y ALBA GONZÁLEZ-PALOMARES

CRITERIOS PARA LA SELECCIÓN DE IMÁGENES SIN ESTEREOTIPOS VINCULADAS CON LA PRÁCTICA DE ACTIVIDAD FÍSICO-DEPORTIVA EN LA EDICIÓN DE LIBROS DE TEXTO

\begin{tabular}{|c|c|c|c|c|c|c|c|c|}
\hline $\begin{array}{c}\text { TIPO } \\
\text { ACTIVIDAD } \\
\text { FÍSICA } \\
\end{array}$ & N..$^{\circ}$ & ÁмBITO & NIVEL & ESPACIO & GÉNERO & EDAD & $\begin{array}{l}\text { ETNIA- } \\
\text { CULTURA }\end{array}$ & DISCPACIDAD \\
\hline \multirow{16}{*}{ 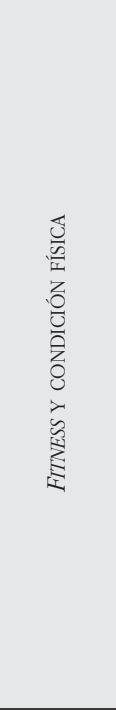 } & 25 & Educativo & No élite & Interior & Mujer & Niñez/adolescencia & Blanca & $\operatorname{Sin}$ \\
\hline & 26 & Educativo & No élite & Interior & Hombre & Niñez/adolescencia & Blanca & Sin \\
\hline & 27 & Educativo & No élite & Interior & $\begin{array}{l}\text { Grupo } \\
\text { mixto }\end{array}$ & Niñez/adolescencia & Multicultural & Disc. \\
\hline & 28 & Educativo & No élite & Exterior & Mujer & Niñez/adolescencia & Blanca & Disc. \\
\hline & 29 & Educativo & No élite & Exterior & Hombre & Niñez/adolescencia & Blanca & $\operatorname{Sin}$ \\
\hline & 30 & Educativo & No élite & Exterior & $\begin{array}{l}\text { Grupo } \\
\text { mixto }\end{array}$ & Persona mayor & Blanca & Sin \\
\hline & 31 & Instrumental & No élite & Interior & Mujer & Joven/adulto & Blanca & Sin \\
\hline & 32 & Instrumental & No élite & Interior & Hombre & Joven/adulto & Blanca & Disc. \\
\hline & 33 & Instrumental & No élite & Interior & Mixto & Persona mayor & Blanca & Sin \\
\hline & 34 & Instrumental & No élite & Interior & Mixto & Joven/adulto & Multicultural & Sin \\
\hline & 35 & Informal & No élite & Interior & Mujer & Persona mayor & Blanca & Sin \\
\hline & 36 & Informal & No élite & Interior & Hombre & Niñez/adolescencia & Blanca & $\operatorname{Sin}$ \\
\hline & 37 & Informal & No élite & Interior & Mixto & Niñez/adolescencia & Blanca & Sin \\
\hline & 38 & Informal & No élite & Exterior & Mujer & Niñez/adolescencia & Blanca & $\operatorname{Sin}$ \\
\hline & 39 & Informal & No élite & Exterior & Hombre & Persona mayor & Blanca & $\operatorname{Sin}$ \\
\hline & 40 & Informal & No élite & Exterior & Mixto & Joven/adulto & Multicultural & Disc. \\
\hline \multirow{4}{*}{ 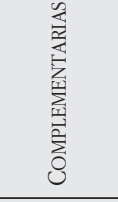 } & 41 & Educativo & No élite & Interior & Hombre & Niñez/adolescencia & Otras & Sin \\
\hline & 42 & Educativo & No élite & Exterior & Mixto & Persona mayor & Blanca & $\operatorname{Sin}$ \\
\hline & 43 & Informal & No élite & Interior & Mixto & Niñez/adolescencia & Blanca & Disc. \\
\hline & 44 & Informal & No élite & Exterior & Mujer & Joven/adulto & Otras & Sin \\
\hline \multirow{4}{*}{ 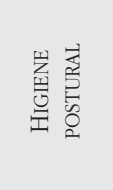 } & 45 & Educativo & No élite & Interior & Mujer & Niñez/adolescencia & Blanca & $\operatorname{Sin}$ \\
\hline & 46 & Educativo & No élite & Exterior & Mixto & Niñez/adolescencia & Blanca & Sin \\
\hline & 47 & Informal & No élite & Interior & Mixto & Persona mayor & Blanca & $\operatorname{Sin}$ \\
\hline & 48 & Informal & No élite & Exterior & Hombre & Joven/adulto & Blanca & $\operatorname{Sin}$ \\
\hline
\end{tabular}


ANA REY-CAO, M. ํㅗㄴ INÉS TÁBOAS-PAIS Y ALBA GONZÁLEZ-PALOMARES

CRITERIOS PARA LA SELECCIÓN DE IMÁGENES SIN ESTEREOTIPOS VINCULADAS CON LA PRÁCTICA DE ACTIVIDAD FÍSICO-DEPORTIVA EN LA EDICIÓN DE LIBROS DE TEXTO

\begin{tabular}{|c|c|c|c|c|c|c|c|c|}
\hline $\begin{array}{c}\text { TIPO } \\
\text { ACTIVIDAD } \\
\text { FÍSICA } \\
\end{array}$ & N. $\stackrel{\circ}{ }$ & ÁMBITO & NIVEL & ESPACIO & GÉNERO & EDAD & $\begin{array}{l}\text { ETNIA- } \\
\text { CULTURA }\end{array}$ & DISCPACIDAD \\
\hline \multirow{24}{*}{ 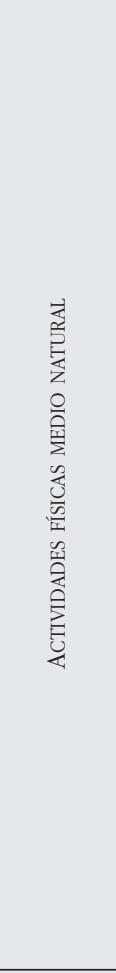 } & 49 & Educativo & No élite & Exterior & Mujer & Niñez/adolescencia & Blanca & Disc. \\
\hline & 50 & Educativo & No élite & Exterior & Hombre & Niñez/adolescencia & Blanca & $\operatorname{Sin}$ \\
\hline & 51 & Educativo & No élite & Exterior & Mixto & Joven/adulto & Blanca & $\operatorname{Sin}$ \\
\hline & 52 & Educativo & No élite & Exterior & Mixto & Niñez/adolescencia & Multicultural & Disc. \\
\hline & 53 & Educativo & No élite & Exterior & Mixto & Niñez/adolescencia & Multicultural & $\operatorname{Sin}$ \\
\hline & 54 & Educativo & No élite & Exterior & Mixto & Niñez/adolescencia & Blanca & $\operatorname{Sin}$ \\
\hline & 55 & Educativo & No élite & Exterior & Mixto & Persona mayor & Blanca & $\operatorname{Sin}$ \\
\hline & 56 & Educativo & No élite & Exterior & Mixto & Persona mayor & Blanca & $\operatorname{Sin}$ \\
\hline & 57 & Competitivo & Élite & Exterior & Mujer & Joven/adulto & Otras & $\operatorname{Sin}$ \\
\hline & 58 & Competitivo & Élite & Exterior & Hombre & Joven/adulto & Blanca & Disc. \\
\hline & 59 & Competitivo & Élite & Exterior & Mujer & Joven/adulto & Blanca & $\operatorname{Sin}$ \\
\hline & 60 & Competitivo & Élite & Exterior & Hombre & Joven/adulto & Blanca & $\operatorname{Sin}$ \\
\hline & 61 & Competitivo & No élite & Exterior & Mujer & Niñez/adolescencia & Blanca & $\operatorname{Sin}$ \\
\hline & 62 & Competitivo & No élite & Exterior & Hombre & Niñez/adolescencia & Blanca & $\operatorname{Sin}$ \\
\hline & 63 & Competitivo & No élite & Exterior & Mujer & Niñez/adolescencia & Blanca & Sin \\
\hline & 64 & Competitivo & No élite & Exterior & Hombre & Niñez/adolescencia & Blanca & $\operatorname{Sin}$ \\
\hline & 65 & Informal & No élite & Exterior & Mujer & Persona mayor & Blanca & $\operatorname{Sin}$ \\
\hline & 66 & Informal & No élite & Exterior & Hombre & Persona mayor & Blanca & $\operatorname{Sin}$ \\
\hline & 67 & Informal & No élite & Exterior & Mixto & Joven/adulto & Otras & $\operatorname{Sin}$ \\
\hline & 68 & Informal & No élite & Exterior & Mixto & Niñez/adolescencia & Multicultural & $\operatorname{Sin}$ \\
\hline & 69 & Informal & No élite & Exterior & Mixto & Niñez/adolescencia & Blanca & Disc. \\
\hline & 70 & Informal & No élite & Exterior & Mixto & Niñez/adolescencia & Blanca & Disc. \\
\hline & 71 & Informal & No élite & Exterior & Mixto & Persona mayor & Blanca & $\operatorname{Sin}$ \\
\hline & 72 & Informal & No élite & Exterior & Mixto & Persona mayor & Blanca & $\operatorname{Sin}$ \\
\hline \multirow{16}{*}{ 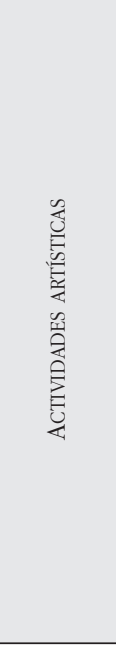 } & 73 & Educativo & No élite & Interior & Mixto & Niñez/adolescencia & Blanca & Disc. \\
\hline & 74 & Educativo & No élite & Interior & Mixto & Niñez/adolescencia & Multicultural & $\operatorname{Sin}$ \\
\hline & 75 & Educativo & No élite & Exterior & Mixto & Niñez/adolescencia & Blanca & Disc. \\
\hline & 76 & Educativo & No élite & Exterior & Mixto & Niñez/adolescencia & Multicultural & Sin \\
\hline & 77 & Escénico & Élite & Interior & Hombre & Joven/adulto & Blanca & $\operatorname{Sin}$ \\
\hline & 78 & Escénico & Élite & Interior & Mixto & Persona mayor & Blanca & Sin \\
\hline & 79 & Escénico & Élite & Exterior & Mixto & Joven/adulto & Otras & Sin \\
\hline & 80 & Escénico & Élite & Exterior & Mujer & Joven/adulto & Blanca & $\operatorname{Sin}$ \\
\hline & 81 & Escénico & No élite & Interior & Mixto & Niñez/adolescencia & Blanca & $\operatorname{Sin}$ \\
\hline & 82 & Escénico & No élite & Interior & Mujer & Joven/adulto & Blanca & Disc. \\
\hline & 83 & Escénico & No élite & Exterior & Mixto & Niñez/adolescencia & Blanca & $\operatorname{Sin}$ \\
\hline & 84 & Escénico & No élite & Exterior & Hombre & Persona mayor & Blanca & $\operatorname{Sin}$ \\
\hline & 85 & Informal & No élite & Interior & Mixto & Niñez/adolescencia & Blanca & $\operatorname{Sin}$ \\
\hline & 86 & Informal & No élite & Interior & Hombre & Niñez/adolescencia & Otras & Disc. \\
\hline & 87 & Informal & No élite & Exterior & Mixto & Niñez/adolescencia & Blanca & Sin \\
\hline & 88 & Informal & No élite & Exterior & Mujer & Persona mayor & Blanca & $\operatorname{Sin}$ \\
\hline
\end{tabular}


ANA REY-CAO, M. ํㅗㅅㅡ TÁBOAS-PAIS Y ALBA GONZÁLEZ-PALOMARES

CRITERIOS PARA LA SELECCIÓN DE IMÁGENES SIN ESTEREOTIPOS VINCULADAS CON LA PRÁCTICA DE ACTIVIDAD FÍSICO-DEPORTIVA EN LA EDICIÓN DE LIBROS DE TEXTO

\begin{tabular}{|c|c|c|c|c|c|c|c|c|}
\hline $\begin{array}{c}\text { TIPO } \\
\text { ACTIVIDAD } \\
\text { FÍSICA } \\
\end{array}$ & N..$^{\circ}$ & ÁмBITO & NIVEL & ESPACIO & GÉNERO & EDAD & $\begin{array}{l}\text { ETNIA- } \\
\text { CULTURA }\end{array}$ & DISCPACIDAD \\
\hline \multirow{8}{*}{ 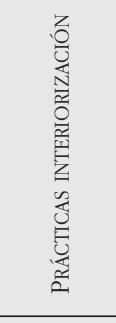 } & 89 & Educativo & No élite & Interior & Mujer & Niñez/adolescencia & Multicultural & Sin \\
\hline & 90 & Educativo & No élite & Interior & Hombre & Niñez/adolescencia & Blanca & Sin \\
\hline & 91 & Educativo & No élite & Interior & Mixto & Joven/adulto & Blanca & $\operatorname{Sin}$ \\
\hline & 92 & Educativo & No élite & Interior & Mixto & Persona mayor & Blanca & Sin \\
\hline & 93 & Informal & No élite & Interior & Mujer & Niñez/adolescencia & Blanca & $\operatorname{Sin}$ \\
\hline & 94 & Informal & No élite & Interior & Hombre & Persona mayor & Blanca & Sin \\
\hline & 95 & Informal & No élite & Exterior & Mujer & Persona mayor & Blanca & Sin \\
\hline & 96 & Informal & No élite & Exterior & Hombre & Joven/adulto & Blanca & Disc. \\
\hline \multirow{2}{*}{ 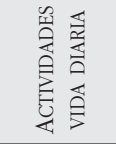 } & 97 & Utilitario & No élite & Interior & Mixto & Niñez/adolescencia & Blanca & $\operatorname{Sin}$ \\
\hline & 98 & Utilitario & No élite & Interior & Mixto & Joven/adulto & Blanca & $\operatorname{Sin}$ \\
\hline \multirow{2}{*}{ 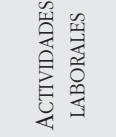 } & 99 & Utilitario & No élite & Interior & Hombre & Joven/adulto & Multicultural & $\operatorname{Sin}$ \\
\hline & 100 & Utilitario & No élite & Interior & Mujer & Joven/adulto & Blanca & Disc. \\
\hline
\end{tabular}

Esta selección de imágenes responde a la distribución de porcentajes con respecto a las variables género, edad, aspecto étnico-cultural, discapacidad, tipo de actividad física, ámbito de práctica, nivel y espacio que se muestran en los diagramas de sectores de la Figura 1. Además, las asociaciones entre los modelos de cuerpo y los modelos de actividad física permiten comprobar que se trata de una propuesta teórica que supera los estereotipos identificados en análisis previos. 
ANA REY-CAO, M. 픈 TN TÁBOAS-PAIS Y ALBA GONZÁLEZ-PALOMARES

CRITERIOS PARA LA SELECCIÓN DE IMÁGENES SIN ESTEREOTIPOS VINCULADAS CON LA PRÁCTICA DE ACTIVIDAD FÍSICO-DEPORTIVA EN LA EDICIÓN DE LIBROS DE TEXTO

\section{FIGURA 1}

Porcentajes de fotografías para las variables género, edad, aspecto étnico-cultural, discapacidad, tipo de actividad física, ámbito de práctica, nivel y espacio

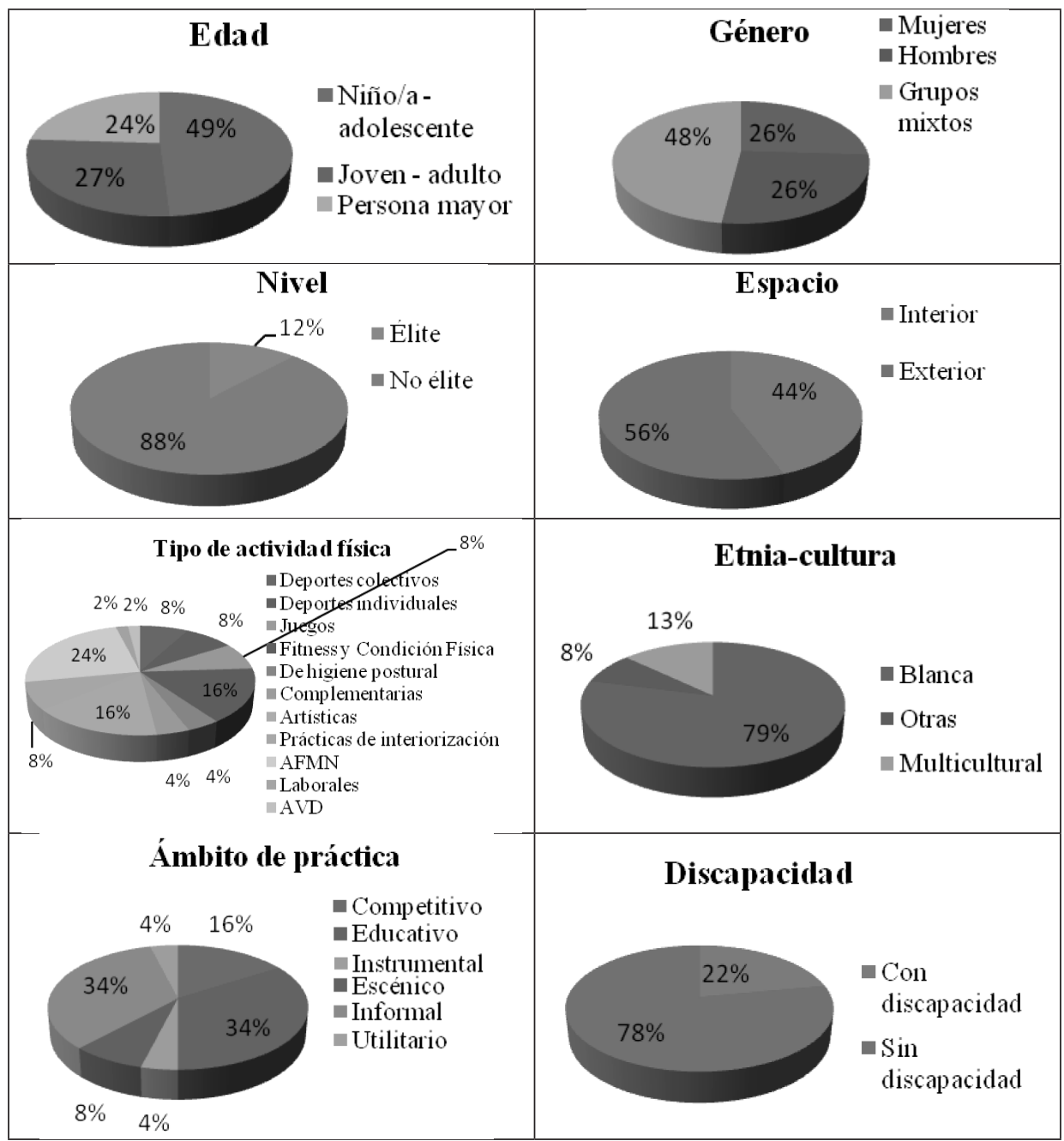


ANA REY-CAO, M. ํㅗㄴ INÉS TÁBOAS-PAIS Y ALBA GONZÁLEZ-PALOMARES

CRITERIOS PARA LA SELECCIÓN DE IMÁGENES SIN ESTEREOTIPOS VINCULADAS CON LA PRÁCTICA DE ACTIVIDAD FÍSICO-DEPORTIVA EN LA EDICIÓN DE LIBROS DE TEXTO

\section{CONCLUSIONES}

Las conclusiones del presente trabajo sobre los contenidos visuales de los libros de texto de EF se resumen en tres aspectos: transmiten prejuicios y estereotipos, no se ajustan a la normativa española en materia de educación y su funcionalidad se incrementaría aplicando criterios operativos para su selección.

Con respecto a la primera de las conclusiones, las imágenes representan mayoritariamente un modelo de cuerpo funcional, masculino, blanco y joven con una tipología corporal media, que oculta la vejez e invisibiliza a las personas con discapacidad.

Investigaciones precedentes sobre libros de texto (Blanco, 2004; Parra, 2002) evidenciaron la existencia de un modelo masculino dominante y la restricción de las mujeres en determinadas prácticas deportivas. En los libros analizados se transmite una masculinidad hegemónica asociada a los deportes, a la condición física y a la aventura; mientras que la femineidad se vincula a las actividades artísticas y a contextos de práctica físico-corporal limitados.

Las personas con una apariencia diferente al endogrupo -blanco y occidentalestán excluidas de las imágenes. Este resultado coincide con trabajos previos sobre libros de texto de otras materias (Morales y Lischinsky, 2008; Torres, 2008) y con los pocos estudios realizados hasta la fecha sobre libros de texto de EF (Botelho et al., 2008). El hecho de que las personas que no responden al modelo eurocéntrico solo se muestren en contextos deportivos de competición de alto rendimiento podría estar reforzando la infundada creencia sobre la superioridad física de la raza negra (Contreras et al., 2008; Harrison et al., 2004). No hay evidencia científica -genética o biológica- que corrobore esta creencia, por lo que los imaginarios sociales como los que configuran los libros de texto (Jorquera, 2011) podrían estar alimentándola (Hayes y Sugden, 1999).

La percepción iconográfica constituye un atractivo modelo de identificación para los y las jóvenes (Revuelta, 2008). La ausencia de personas mayores en ámbitos habituales para el alumnado reproduce ideas negativas sobre la vejez. Puede llevarles a percibir que las personas mayores no forman parte de su mundo y que son menos capaces de participar en algunas actividades (Robinson et al., 2007).

Las personas con discapacidad y las actividades físicas adaptadas sólo se representan de forma esporádica. Este hecho, demostrado con anterioridad por autores como Botelho et al. (2008), Hardin y Hardin (2004), Sleeter y Grant (2011) y Torres (2008), contribuye a su invisibilidad, exclusión y al refuerzo de desigualdades.

Los deportes tradicionales y los ejercicios para la mejora de la condición física se imponen en las imágenes. Esta representación limita la gran diversidad de expresiones motrices a aquellas que responden a la lógica de una cultura corporal funcional propia de la "modernidad líquida" (Bauman, 2000). La EF y el deporte se 
ANA REY-CAO, M.ํㅗNÉS TÁBOAS-PAIS Y ALBA GONZÁLEZ-PALOMARES

CRITERIOS PARA LA SELECCIÓN DE IMÁGENES SIN ESTEREOTIPOS VINCULADAS CON LA PRÁCTICA

DE ACTIVIDAD FÍSICO-DEPORTIVA EN LA EDICIÓN DE LIBROS DE TEXTO

convierten en prácticas insertas en dispositivos de control y regulación de la población como parte del proceso de consolidación del capitalismo: la función biomédica y normalizadora de la originaria educación física moderna (Crisorio, 2007), la función de globalización del deporte de masas (Mella, 2010) o la actual funcionalidad individualizadora del ejercicio físico y las prácticas de fitness, "las imperfecciones de mi cuerpo son mi culpa y mi vergüenza. Pero la redención de los pecados solo está -y exclusivamente- en manos del pecador" (Bauman, 2000: 73).

La segunda conclusión se refiere a la inadecuación de los contenidos visuales a la normativa española en materia de educación. Los resultados ponen de manifiesto que no son acordes a lo que dispone la LOE en su disposición adicional cuarta: no se adecuan al currículo y no respetan los valores de igualdad y no discriminación establecidos en la ley respecto al género, la multiculturalidad, la edad y la discapacidad. Por tanto, no parecen haberse sometido a una supervisión por parte de la administración educativa que vele por el respeto a los principios y valores contenidos en la Constitución y a lo dispuesto en la presente ley.

La tercera conclusión señala que es posible incrementar la funcionalidad de los libros de texto (De la Orden, 2009) aplicando los criterios de evaluación de imágenes que se exponen en los resultados. Los criterios superan los estereotipos evidenciados en esta investigación y optimizan la funcionalidad del sistema educativo. Logran estos objetivos porque permiten una selección de contenidos visuales para los libros de texto acordes a las metas y valores que ha de transmitir al sistema educativo. Para su elaboración se contrastaron las características de la cultura corporal presentes en las imágenes de los libros de texto con las finalidades del sistema educativo. La aportación principal de este trabajo es que, tal y como reclamaba Colás (1989), recoge parámetros concretos que sirven como herramienta básica de reflexión, análisis, elaboración y selección de materiales didácticos.

Una selección de imágenes sin estereotipos vinculadas con la práctica de actividad físico-deportiva para la edición de un libro de texto puede realizarse tomando como referencia una distribución equilibrada de porcentajes con respecto a las variables género, edad, aspecto étnico-cultural, discapacidad, tipo de actividad física, ámbito de práctica, nivel y espacio. Estas variables fundamentales deben combinarse de forma equilibrada y asociarse con una distribución proporcionada entre los modelos de cuerpo y la indumentaria de sus protagonistas.

Los criterios de evaluación incorporan la dimensión editorial y la dimensión docente. Son susceptibles de ser aplicados en la selección de imágenes para la edición de libros de texto y también en la selección que profesores y profesoras realizan para el uso y aplicación de materiales visuales en el aula.

Los criterios elaborados pueden aplicarse para la selección de fotografías destinadas a manuales de diferentes áreas de conocimiento en las que aparezcan representadas personas vinculadas a la práctica de actividad físico-deportiva. 


\section{REFERENCIAS BIBLIOGRÁFICAS}

Acaso, M. y Nuere, S. (2005). El currículum oculto visual: aprender a obedecer a través de la imagen. Arte, Individuo y Sociedad, 17, 205-218.

Atienza, E. (2007). Discurso e ideología en los libros de texto de ciencias sociales. Discurso y Sociedad, 1 (4), 543-574. http://www.dissoc.org/ediciones/v01n04/DS1\%284\%29Atienza.html.

Bauman, Z. (2000). Modernidad líquida. Buenos Aires: Fondo de Cultura Económica de Argentina.

Blanco, N. (2004). Cultures of schooling. No place for women? En F. Hernández e I. F. Goodson (Eds.). Social geographies of educational change (pp. 79-90). Dordrecht: Kluwer Academic Publishers.

Botelho, P.; Silva, P.; Queirós, T. y Caetano, S. (2008). Manuais de educação física: em rota de colisão com género, diversidade e cidadania? En F. Henriques (Ed.). Género, diversidade e cidadania (pp. 89-101). Lisboa, Portugal: Colibri.

Colás, P. (1989). El libro de texto y las ilustraciones: enfoques y perspectivas en la investigación educativa. Enseñanza \& Teaching, 7, 41-49. http://campus.usal.es/ revistas_trabajo/index.php/0212-5374/article/view/3461/3480.

Contreras, O. R.; Pastor, J. C. y González, S. (2008). La influencia de los deportistas de élite en las actitudes y estereotipos racistas de los escolares. Tándem: Didáctica de la Educación Física, 28, 27-38.

Crisorio, R. (2007). Educación física y biopolítica. Temas y Matizes, 11, 67-78. http://e-revista.unioeste.br/index.php/temasematizes/article/view/2504/1878.

De la Orden, A. (2009). Evaluación y calidad: análisis de un modelo. Estudios sobre Educación, 16, 17-36.

Ferrante, C. (2010). Rengueando el estigma: Modos de ser, pensar y sentir (se) discapacitado construidos desde la práctica deportiva adaptada. Revista brasileira de sociologia da emoção, 9 (27), 980-1009. http://www.cchla.ufpb.br/grem/CarolinaArt.pdf.

Giner, A.; Martínez, M. ․ A. y Sauleda, N. (2009). La cultura escolar inscrita en los anuncios televisivos. Enseñanza \& Teaching, 27 (1), 191-206. http://campus.usal.es/ revistas_ rabajo/index.php/0212-5374/article/view/6590/7150.

Goldstein, S. B.; Siegel, D. y Seaman, J. (2009). Limited access: The status of disability in introductory psychology textbooks. Teaching of Psychology, 37 (1), 21-27. http://dx.doi.org/10.1080/00986280903426290.

González, A.; Táboas, M. ํㅗ. y Rey, A. (2010). Los libros de texto como herramientas para la promoción de una práctica físico-deportiva en igualdad: análisis comparativo de la representación racial entre los libros publicados durante la vigencia de la LOGSE y la LOE. Cuadernos de Psicología del Deporte, 10, 31-36.

González-Palomares, A. y Rey-Cao, A. (2013). Cultura corporal y estereotipos en las imágenes de libros de texto de educación física publicados bajo el periodo de la Ley Orgánica de Educación (LOE). Ágora para la Educación Física y el Deporte, 15 (1), 1-19.

Hardin, B. y Hardin, M. (2004). Distorted pictures: Images of disability in physical education textbooks. Adapted Physical Activity Quarterly, 21, 399-413.

Harrison, L.; Azzarito, L. y Burden, J. (2004). Perceptions of athletic superiority: a view from the other side. Race, Ethnicity and Education, 7 (2), 149-166. http://dx.doi.org/10.1080/1361332042000234277

Hayes, S. y Sugden, J. (1999). Winning through 'Naturally' Still? An Analysis of the Perceptions Held by Physical Education Teachers towards the Performance of Black Pupils 
ANA REY-CAO, M. ํㅗㄴ INÉS TÁBOAS-PAIS Y ALBA GONZÁLEZ-PALOMARES

CRITERIOS PARA LA SELECCIÓN DE IMÁGENES SIN ESTEREOTIPOS VINCULADAS CON LA PRÁCTICA

DE ACTIVIDAD FÍSICO-DEPORTIVA EN LA EDICIÓN DE LIBROS DE TEXTO

in School Sport and in the Classroom. Race, Ethnicity and Education, 2 (1), 93-107. http://dx.doi.org/10.1080/1361332990020107.

Instituto Nacional de Estadística [INE] (2009). Panorámica de la discapacidad en España. Encuesta de Discapacidad, Autonomía personal y situaciones de Dependencia. 2008. Cifras INE. Boletín informativo del Instituto Nacional de Estadística, 10/2009. http://www.ine.es/revistas/cifraine/1009.pdf.

Jorquera, P. (2011). Vejez y envejecimiento: Imaginarios sociales presentes en los textos escolares oficiales del Ministerio de Educación chileno. Revista MAD, 0 (22). Recuperado de http://www.revistas.uchile.cl/index.php/RMAD/article/viewArticle/13642/13921. http://dx.doi.org/10.5354/0718-0527.2010.13642.

Knudsen, S. (2005). Intersectionality. A theoretical inspiration in the analysis of minority cultures and identities in textbooks. En E. Bruillard, B. Aamotsbakken, S. V. Knudsen y M. Horsley (Eds.). Caught in the web or lost in the textbook? Eighth International Conference on Learning and Educational Media (pp. 61-76). Caen, FRA: Larten. Recuperado de http://www.iartem.no/documents/caught_in_the_web.pdf.

Lee, J. F. K. y Collins, P. (2008). Gender voices in Hong Kong English textbooks-some past and current practices. Sex Roles, 59, 127-137.

http://dx.doi.org/10.1007/s11199-008-9414-6.

Ley Orgánica 2/2006, de 3 de mayo, de Educación. BOE n.ำ 106, de 4 de mayo de 2006.

Luengo, M. R. y Blázquez, F. (2004). Género y libros de texto. Un estudio de estereotipos en las imágenes. Badajoz: Junta de Andalucía.

Mella, M. (2010). Fútbol y subdesarrollo. Temas para el Debate, 188, 64-66.

Moeglin, P. (2005). The Textbook and after... En E. Bruillard, B. Aamotsbakken, S. V. Knudsen y M. Horsley (Eds.). Caught in the Web or Lost in the Textbook? Eighth International Conference on Learning and Educational Media (pp. 15-33). Caen, FRA: Iartem. Recuperado de http://www.iartem.no/documents/caught_in_the_web.pdf.

Morales, O. y Lischinsky, A. (2008). Discriminación a través de las ilustraciones de libros de texto de Enseñanza Secundaria Obligatoria en España. Discurso y Sociedad, 2 (1), $115-152$.

http://www.dissoc.org/ediciones/v02n01/DS2\%281\%29Morales\%20y\%20Lischinsky.pdf

Parra, J. (2002). Análisis del sexismo en los libros de texto de educación física: $2^{\circ}$ ciclo de ESO y bachillerato (tesis doctoral). España: UNED.

Revuelta, J. (2008). Pedagogía de la imagen: lectura crítica de publicidad televisiva. Comunicar. Revista Científica de Educomunicación, 31 (16), 613-621.

http://dx.doi.org/10.3916/c31-2008-03-058.

Rey-Cao, A.; Táboas-Pais, A. y Canales-Lacruz, I. (2013). La representación de las personas mayores en los libros de texto de educación física. Revista de Educación, 362, 129-153. http://dx.doi.org/10.1016/i.jaging.2006.10.001.

Robinson, T.; Callister, M.; Magoffin, D. y Moore, J. (2007). The Portrayal of Older Characters in Disney Animated Films. Journal of Aging Studies, 21 (3), 203-213.

http://dx.doi.org/10.1016/j.jaging.2006.10.001.

Romero, C. (2003). Los desplazamientos de la "raza": de una invención política y la materialidad de sus efectos. Politica y Sociedad, 40 (1), 111-128.

Ruiz, U. y Camps, A. (2009). Investigar los géneros discursivos en el proceso educativo. Revista de Psicodidáctica, 14 (2), 211-228.

http://dx.doi.org/10.1387/RevPsicodidact.725.

(c) Ediciones Universidad de Salamanca

Enseñanza \& Teaching, 32, 2-2014, pp. 73-96 
ANA REY-CAO, M. ํㅗㄴ IN TÁBOAS-PAIS Y ALBA GONZÁLEZ-PALOMARES

CRITERIOS PARA LA SELECCIÓN DE IMÁGENES SIN ESTEREOTIPOS VINCULADAS CON LA PRÁCTICA DE ACTIVIDAD FÍSICO-DEPORTIVA EN LA EDICIÓN DE LIBROS DE TEXTO

Sleeter, C. E. y Grant, C. A. (2011). Race, class, gender and disability in current textbooks. En E. F. Provenzo, A. N. Shaver y M. Bello (Eds.). The textbook as discourse. Sociocultural dimensions of American schoolbooks (pp. 183-215). New York: Routledge.

Táboas, M. ․ I. (2009). Análisis de los estereotipos corporales y de los modelos de actividad física representados en las imágenes de los libros de texto de Educación Física. (Tesis doctoral, Universidade de Vigo, 2009).

Táboas, M.ํㅡ I. y Rey, A. (2011a). Las imágenes de los libros de texto de educación física: percepción y opinión del alumnado. Tándem. Didáctica de la Educación Física, 36, $103-111$.

Táboas, M. ${ }^{a}$ I. y Rey, A. (2011b). Los modelos corporales en la actividad física y el deporte: hacia una superación de los estereotipos desde la educación física escolar. Revista Española de Educación Física y Deportes, 392, 99-118.

Táboas, M. ${ }^{a}$ I. y Rey, A. (2012). Los contenidos de la Educación Física en Secundaria: un análisis de las actividades físicas que se enseñan en las imágenes de los libros de texto. Apunts, educación fisica y deportes, 107. http://dx.doi.org/10.5672/apunts.2014-0983.es.(2012/1).107.04.

Táboas-Pais, M. ${ }^{\underline{a}}$ I. y Rey-Cao, A. (2012a). Gender Differences in Physical Education Textbooks in Spain: A Content Analysis of Photographs. Sex Roles, 67, 389-402. http://dx.doi.org/10.1007/s11199-012-0174-y.

Táboas-Pais, M..$^{\underline{a}}$ I. y Rey-Cao, A. (2012b). Disability in Physical Education Textbooks: An Analysis of Image Content. Adapted Physical Activity Quarterly, 29 (4), 310-328.

Torres, J. (2008). Diversidad cultural y contenidos escolares. Revista de Educación, 345, 83-110.

UNESCO (1995). Guidelines and Criteria for the Development, Evaluation and Revision of Curricula, Textbooks and other Educational Materials in International Education in Order to Promote an International Dimension in Education. Paris: UNESCO. http://unesdoc.unesco.org/images/0010/001001/100178m.pdf. 